\title{
Effects of Angelica Extract on Schwann Cell Proliferation and Expressions of Related Proteins
}

\author{
Xiaowen Jiang, ${ }^{1}$ Lin Liu, ${ }^{1}$ Binqing Zhang, ${ }^{1}$ Ziyin Lu, ${ }^{1}$ Lu Qiao, ${ }^{1}$ \\ Xinxin Feng, ${ }^{1}$ and Wenhui $\mathbf{Y u}^{1,2}$ \\ ${ }^{1}$ College of Veterinary Medicine, Northeast Agricultural University, Harbin 150030, China \\ ${ }^{2}$ Key Laboratory of the Provincial Education, Department of Heilongjiang for Common Animal Disease Prevention and Treatment, \\ Northeast Agricultural University, Harbin 150030, China
}

Correspondence should be addressed to Wenhui Yu; yuwenhui@neau.edu.cn

Received 12 March 2017; Accepted 25 May 2017; Published 18 July 2017

Academic Editor: Raffaele Capasso

Copyright (C) 2017 Xiaowen Jiang et al. This is an open access article distributed under the Creative Commons Attribution License, which permits unrestricted use, distribution, and reproduction in any medium, provided the original work is properly cited.

\begin{abstract}
The present study investigated the effects of Angelica extract (AE) on Schwann cell proliferation and expressions of related proteins, including brain derived neurotrophic factor (BDNF), neural cell adhesion molecule (NCAM), and proliferating cell nuclear antigen (PCNA). Proliferation activity and cell cycles of SCs were evaluated by MTT assay and flow cytometry methods, respectively, after $12 \mathrm{~h}$ treatment of $\mathrm{AE}$ at different concentrations $(62.5,125,250,1000,2000,4000$, and $8000 \mathrm{mg} / \mathrm{L})$. SCs were treated by 500, 1000, and $2000 \mathrm{mg} / \mathrm{L} \mathrm{AE}$ for $24 \mathrm{~h}$ or $48 \mathrm{~h}$; the related genes mRNA and proteins expressions in SCs were detected by quantitative realtime reverse transcription-polymerase chain reaction (RT-PCR) and enzyme-linked immunosorbent assay (ELISA) kit. At the concentration range of 125-2000 mg/L, the SC proliferation was induced by AE in a dose-dependent manner, especially 1000 and $2000 \mathrm{mg} / \mathrm{L}$; cells in drug-treated groups showed the most increase. Cells counts were ascended significantly in (G2/M + S) phase compared to control group. BDNF, NCAM, and PCNA protein expressions significantly increased at drug-treated groups. Relative genes mRNA expressions levels were also significantly higher compared to control group. The results indicated that $\mathrm{AE}$ facilitated SC proliferation and related genes and proteins expressions, which provided a basic guideline for nerve injury repair in clinic.
\end{abstract}

\section{Introduction}

Schwann cells (SCs) are unique glial cells in the peripheral nervous system and they play vital roles in generation, development, morphology, maintaining function, and other aspects of peripheral nerves [1]. SCs are important for the regeneration and repairment of peripheral nerve injury [2]. When distal site of injured nerve witnessed Waller degeneration, SCs began to proliferate and then participated in swallowing degeneration of axons and myelin debris forming a longitudinal continuous cell cord (Büngner's band), which guided the growth of regenerating axons. SCs are essential for regeneration of microenvironment [3], which is the important condition for neuronal survival and neurite growth. SCs have nutrition effects on neuron due to synthetic neurotrophic factors, and they also contribute to generating neurite growth factors [4]. SCs secrete a variety of neurotrophic factors, such as nerve growth factor (NGF), fibroblast growth factor (FGF), BDNF, NCAM, PCNA, and ciliary neurotrophic factor (CNTF). These factors play major roles in peripheral nerve cell growth, development, regeneration, and maintaining normal nerve cells alive, and they are beneficial to axons regeneration and myelination $[5,6]$. Lack of neurotrophic factors may cause neurological diseases and failure of nerve regeneration [7].

Angelica, Umbelliferae Angelica sinensis (Oliv.) Diels dried roots, is regarded as a traditional natural medicine for invigorating the circulation of blood. Currently, many researches showed that Angelica had a variety of pharmacological effects, including anti-inflammatory [8], anticancer [9], wound healing [10], and nerve regeneration [11] effects. Nerve injury is a common clinical disease; as the research on the treatment of the disease gradually increases, more and more natural plants were applied in peripheral nerve repair. It was reported that natural plants showed fewer side effects and minimize drug resistance [12]. Some studies 
have demonstrated the effects of Angelica on nerve repair. It was also reported that $\mathrm{AE}$ attenuated neuropathic pain, which is associated with proinflammatory cytokines such as tumor necrosis factor- $\alpha$ (TNF- $\alpha$ ), interleukin- $1 \beta$ (IL-1 $\beta$ ) and interleukin-6 (IL-6), TRPV1, and p-ERK in peripheral nervous pain systems [13]. Some findings suggested that Angelica injection improved the sciatic nerve crush injury, and the mechanism might be through the increase of BDNF and NGF protein expressions [14]. Angelica dahuricae radix decreased the levels of TNF- $\alpha$, IL- $1 \beta$, IL- 6 , inducible nitric oxide synthase (iNOS), and cyclooxygenase-2 (COX-2) in a lipopolysaccharide- (LPS-) activated microglial cell line and provided neuroprotection by alleviating inflammation and oxidative stress [15]. Another research elucidated that AE promoted PC12 cell proliferation in vitro assay [16]. The AE contains volatile oil, organic acids, polysaccharides, flavonoids, and other ingredients [17]. These findings showed that Angelica exerted a positive-effect in nerve injury repair. However, the studies of AE in vitro assays are not common, and particularly effects of AE on SCs (important peripheral nerve cells) have not been reported. In the present study, we investigated the effects of $\mathrm{AE}$ on SC proliferation and cycle, protein, and mRNA expressions of BDNF, NCAM, and PCNA, which are related to peripheral nerve repair [18-20]. The detection of these neural factors in AE-treated SCs will provide a mechanistic framework for further studies of the use of $\mathrm{AE}$ as an effective treatment for peripheral nerve injury.

\section{Materials and Methods}

2.1. Equipment and Reagents. HB050 type inverted phase contrast microscope was manufactured by Zeiss company; K330 refrigerated centrifuge was manufactured by Sigma Corporation; iMark550 microplate reader was manufactured by Bio-Rad company; BD flow cytometer was manufactured by American companies. GeneQuant 1300 spectrophotometer was manufactured by General Electric Company. LightCycler 96 was produced by Roche in Switzerland.

AE was purchased from Baoji FangSheng Biological Development Co., Ltd. Rat SCs (RSC96) were obtained from China Cell Line Repository. Dulbecco Modified Eagle Medium (DMEM) was purchased from HyClone company. Fetal Bovine Serum (FBS) was purchased from Sijiqing company in China. MTT and Propidium Iodide (PI) reagents were purchased from American Sigma company. Rat BDNF, NCAM, and PCNA-ELISA kits were produced by Beyotime Institute of Biotechnology in JiangSu. First-strand cDNA synthesis kit was purchased from Thermo Scientific Company. All primers were designed and synthesized by Invitrogen Biotechnology Co., Ltd. (Shanghai, China).

2.2. Cell Toxic Assays. The fifth passage of SCs was used for experiments, and the trypsinized cells were diluted with Dulbecco Modified Eagle Medium (DMEM) containing 10\% Fetal Bovine Serum (FBS) to cell suspension at a concentration of $5.0 \times 10^{4}$ cells $/ \mathrm{mL}$. SCs were seeded in 96-well culture plates and $200 \mu \mathrm{L}$ cell suspension was added to every well. Cells were incubated at $37^{\circ} \mathrm{C}$ under $5 \% \mathrm{CO}_{2}$ for $24 \mathrm{~h}$, then the medium was removed and DMEM without FBS was added per well, and cells were hungered for $12 \mathrm{~h}$ and were randomly divided into control group and drug-treated groups. The control group and drug-treated groups were cultured dividedly by DMEM containing $10 \%$ FBS without or with the medium containing indicated concentrations (62.5, $125,250,1000,2000,4000$, and $8000 \mathrm{mg} / \mathrm{L}$ ) of AE for $12 \mathrm{~h}$ at $37^{\circ} \mathrm{C}$. Cell viability was measured by MTT assay. Five parallel wells were set up for a group and the MTT assay was repeated 3 times.

2.3. The Effects of AE on Proliferation of SCs. SCs growth was interfered with by $\mathrm{AE}$ with the indicated concentration that increased SC proliferation positively. SCs treated by DMEM containing $10 \%$ FBS acted as control, and all groups are set up with 7 parallel wells. The experiments were performed for duplicating at least three times. Cells were cultured for $12 \mathrm{~h}$, $24 \mathrm{~h}, 36 \mathrm{~h}$, and $48 \mathrm{~h}$. The effects of AE on cell proliferation were evaluated by MTT assay as previously described.

2.4. The Effects of AE on the Cell Cycles of SCs. SCs in logarithmic phase were trypsinized and centrifuged; SCs were diluted with DMEM containing 10\% FBS and seeded in $25 \mathrm{~mm}^{3}$ glass screw-cap cell bottle at a density of $2.0 *$ $10^{5}$ cells $/ \mathrm{mL}$. After $24 \mathrm{~h}$ of incubation at $37^{\circ} \mathrm{C}$, the medium was removed and then cells were treated with DMEM for $12 \mathrm{~h}$. In the drug-treated groups, AE mixed with DMEM containing FBS was added to every well at a concentration that promoted cell proliferation, and the cells in control group were only treated by DMEM containing FBS. The supernatant was discarded after incubating for $24 \mathrm{~h}$ and $48 \mathrm{~h}$. The cell cycle of each group was detected by flow cytometry. Modfit LT software was used for analyzing cell cycle of each group. The experiments were performed for repeating at least three times.

2.5. Effects of $A E$ on Expressions of BDNF, NCAM, and $P C N A$ in SCs. SCs growths were interfered with by $\mathrm{AE}$ with the concentrations which promoted SC proliferation, and then cells were cultured for $24 \mathrm{~h}$ and $48 \mathrm{~h}$, respectively. Then the number of SCs was counted, and the culture supernatants were collected to determine the amount of BDNF, NCAM, and PCNA secreted by the cultured SCs. Cell culture supernatants were centrifuged and assayed by using an ELISA kit, following the manufacturer's instructions; cells were trypsinized and cell supernatants were treated according to manufacturer's instruction of ELISA. The protein samples were stored at $-80^{\circ} \mathrm{C}$ until being assayed. The samples were used to measure BDNF, NCAM, and PCNA. The experiment was repeated three times.

2.6. Effects of AE on Gene Expression of BDNF, NCAM, and $P C N A$. SCs were treated by AE for $48 \mathrm{~h}$ at concentrations of 500,1000 , and $2000 \mathrm{mg} / \mathrm{L}$, respectively. Total RNA was isolated from SCs using TRIzol reagent according to the manufacturer's instructions. The RNA concentration was determined using a GeneQuant 1300 spectrophotometer, and the purity of RNA was determined using the $260 / 280 \mathrm{~nm}$ absorbance ratio. The $A 260 / A 280$ ratio of the RNA samples 
TABLe 1: Primers used for RT-PCR.

\begin{tabular}{lccc}
\hline Gene & Serial & Primer $\left(5^{\prime} \rightarrow 3^{\prime}\right)$ & Product size \\
\hline BDNF & NM_001270638.1 & Forward: CGGTATCAAAAGGCCAACTG & 121 bp \\
& & Reverse: GTAGTTCGGCATTGCGAGTT & 122 bp \\
NCAM & NM_031521.1 & Forward: AACGGACTCCAAACCATGAC & \\
& & Reverse: TGGCTTTGCTTCTGACTCCT & 115 bp \\
PCNA & NM_022381.3 & Forward: TTGGAATCCCAGAACAGGAG & \\
& & Reverse: TTTGCACAGGAGATCACCAC & 165 bp \\
B-Actin & NM_031144.3 & Forward: TGTCACCAACTGGGACGATA & \\
\hline
\end{tabular}

was 1.8-2.0. First-strand cDNA was synthesized from $5 \mu \mathrm{g}$ of total RNA according to the manufacturer's instructions. All primers were designed and synthesized by Invitrogen Biotechnology Co., Ltd. The primers used are shown in Table 1.

RT-PCR was performed using a LightCycler 96. The annealing temperatures and the thermocycling conditions for the target genes were as follows: $\operatorname{BDNF}\left(57.9^{\circ} \mathrm{C}, 35\right.$ cycles), $\operatorname{NCAM}\left(57.9^{\circ} \mathrm{C}, 35\right.$ cycles $), \operatorname{PCNA}\left(57.9^{\circ} \mathrm{C}, 35\right.$ cycles $)$, and $\beta$ actin $\left(59^{\circ} \mathrm{C}, 35\right.$ cycles). The standard PCR conditions were as follows: $94^{\circ} \mathrm{C}$ for $30 \mathrm{~s}$ and 45 cycles of $94^{\circ} \mathrm{C}$ for $5 \mathrm{~s}$, a variable annealing temperature for $15 \mathrm{~s}$ and $72^{\circ} \mathrm{C}$ for $10 \mathrm{~s}$. The experiments were performed in triplicate and repeated at least three times. Mean Ct values were used to calculate the relative expression levels of the target genes for the experimental groups, relative to those in the negative control group. The relative expression of target genes was obtained using the $2^{-\Delta \Delta \mathrm{Ct}}$ formula using $\beta$-actin as a housekeeping gene.

2.7. Statistical Analyses. All data were presented as mean values \pm standard deviation, and statistical analysis was performed using a SPSS 13.0 statistical package. The multiple comparisons of data were performed by one-way ANOVA followed by Dunnett's test. Significant differences were defined at values of $P<0.05$ and extreme significant differences were defined at values of $P<0.01$.

\section{Results}

3.1. AE Stimulated SC Proliferation at Indicated Concentration. SC proliferation is important for the healing of nerve injury. Cell toxic assays were preformed to explore effects of AE on SC proliferation. According to Figure 1, result of cell toxic assay showed that, after treatment with different concentrations of $\mathrm{AE}$, the concentration range of $\mathrm{AE}$ which was conducive to the growths of SCs was 125-2000 mg/L and showed dose-dependent manner, and when concentration of AE was lower than $125 \mathrm{mg} / \mathrm{L}$, the SCs growths in drug-treated groups and control group had no significant differences. However, when AE concentration was higher than $4000 \mathrm{mg} / \mathrm{L}$, SC proliferation was inhibited significantly compared to the control group $(P<0.05)$. Therefore, these findings indicated that AE stimulated SC proliferation at appropriate concentration range and the optimal concentration was $1000 \mathrm{mg} / \mathrm{L}$.

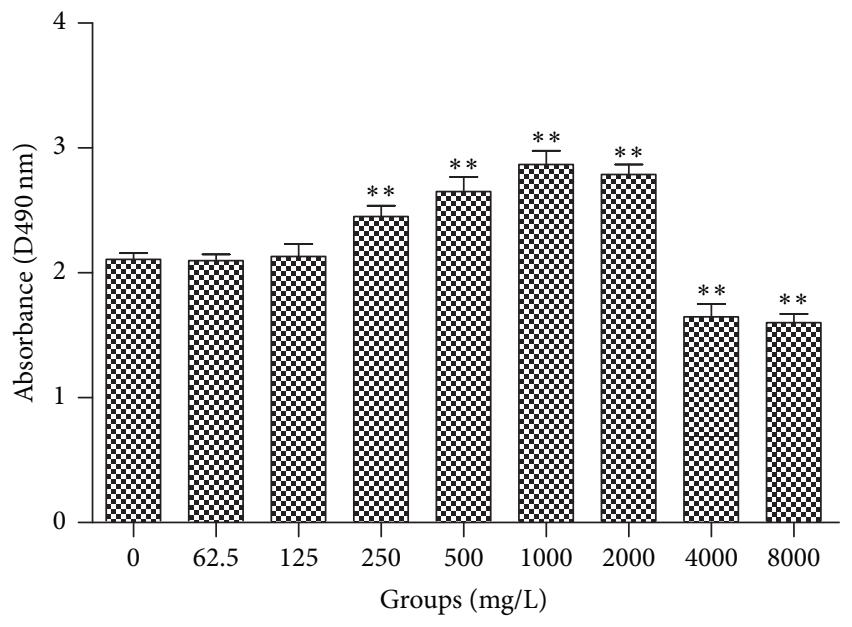

FIgure 1: Cell toxic effects of AE on SCs $(n=6, \pm s)$. This photograph showed SC viability after $12 \mathrm{~h}$ treatment with different concentrations of AE. DMEM with 10\% FBS was used as control. Notes: ${ }^{*} P<0.05,{ }^{* *} P<0.01$, versus the control group (Student's $t$-test).

3.2. AE Promoted SC Proliferation at Different Time Points. Through the cytotoxicity test, the effective concentrations of AE were determined. To further study the effects on SC proliferation at different time points with treatment of $\mathrm{AE}$, cell proliferation test was performed. As shown in Figure 2, when AE concentration was in the 250-2000 mg/L range, AE promoted SC proliferation after treating for $24 \mathrm{~h}, 48 \mathrm{~h}$, and $72 \mathrm{~h}$; at a concentration of 500-2000 $\mathrm{mg} / \mathrm{L}$, cell proliferation in different groups was significantly increased by comparison with control group $(P<0.05)$; when the concentrations were 1000 and $2000 \mathrm{mg} / \mathrm{L}$, drug-treated groups showed the extremely significant difference compared to control group $(P<0.01)$.

3.3. The Effects of AE on the Cell Cycles of SCs. We examined the cell cycle in AE-treated SCs. The G2 phase is the late stage of DNA synthesis and the M phase is the stage of mitosis, and they all reflect the state of cell proliferation to some extent. As shown in Figures 3 and 4, SCs were treated by 500,1000 , and $2000 \mathrm{mg} / \mathrm{L}$ concentrations of AE for $24 \mathrm{~h}$ or $48 \mathrm{~h}$, compared with control group, and the results showed that cells percentage composition had differences in G0/G1, $\mathrm{S}$, and $\mathrm{G} 2 / \mathrm{M}$ phase, respectively. Moreover, we found that 

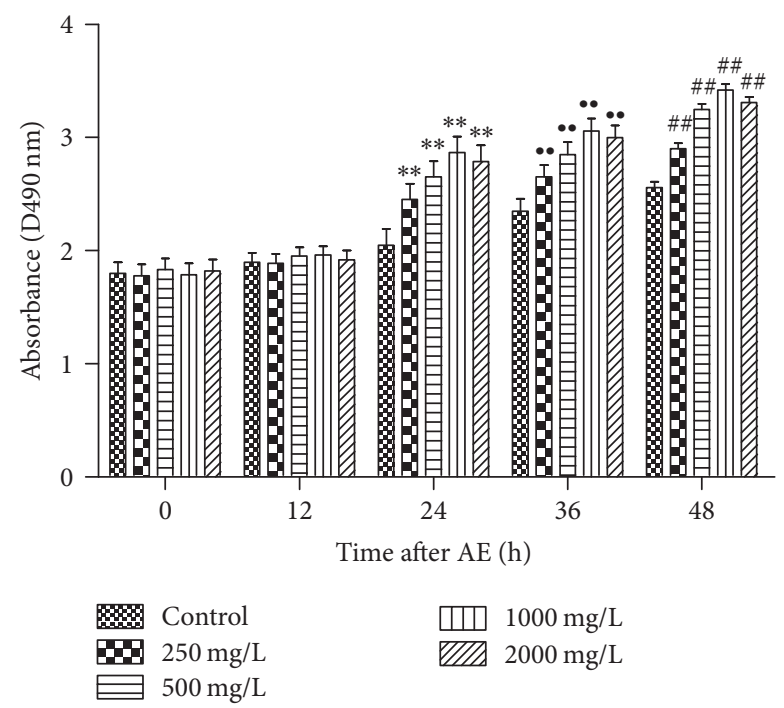

FIGURE 2: Drug concentration and application time effects on SC proliferation $(n=12, \pm \mathrm{s})$. The viability of SC at $0 \mathrm{~h}, 12 \mathrm{~h}$, $24 \mathrm{~h}, 36 \mathrm{~h}$, and $48 \mathrm{~h}$ was assessed after being treated with different concentrations $(250 \sim 2000 \mathrm{mg} / \mathrm{mL})$ of AE. Notes: ${ }^{* *, \cdots, \# \#} P<0.01$ versus control group at the same time (Student's $t$-test).

the proliferation index $(\mathrm{PI}=\mathrm{S}+\mathrm{G} 2 / \mathrm{M})$ was significantly increased. The percentage of drug-treated cells in (G2/M + S) phase was higher than control group $(P<0.01)$, and this finding showed that $\mathrm{AE}$ activated synthesis of DNA, which leads to cell proliferation (Figure 5).

\subsection{AE Increased BDNF, NCAM, and PCNA Protein Expres-} sions in SCs. Expressions of BDNF, NCAM, and PCNA protein are important for regeneration of nerve. The ELISA assays were performed. When AE concentration was $1000 \mathrm{mg} / \mathrm{L}, \mathrm{BDNF}$ and PCNA contents in cells were checked after incubating for $24 \mathrm{~h}$, and the results showed significant difference compared with control group $(P<0.05)$; the expression of PCNA in cells cultured for $48 \mathrm{~h}$ were detected, and these results revealed that drug-treated cells expressed more PCNA protein compared with cells in control group $(P<0.01) .2000 \mathrm{mg} / \mathrm{L}$ of AE-treated cells for $24 \mathrm{~h}$ and expressions of BDNF and PCNA were extremely significant higher than control group $(P<0.01)$. NCAM was upregulated significantly compared with the control group $(P<0.05)$. After incubation of $48 \mathrm{~h}$, expressions of BDNF, NCAM, and PCNA increased obviously compared with the control group $(P<0.01)$, and all were shown in Figure 6.

3.5. AE Promoted Relative Genes Expressions in SCs. To further examine the effects of AE on BDNF, NCAM, and PCNA, gene expressions were checked. 500, 1000, and $2000 \mathrm{mg} / \mathrm{L}$ of AE interfered with cells growths for $48 \mathrm{~h}$, RNA purity was detected, and generally the extracted RNA are available when the detection results belong to 1.8-2.0. As shown in Figure 7, AE at concentrations of 500, 1000, and $2000 \mathrm{mg} / \mathrm{L}$ all effectively promoted the gene expressions of BDNF, NCAM, and PCNA compared with control group $(P<0.01)$, and expressions of these genes had the most significant increase when concentration of AE was $1000 \mathrm{mg} / \mathrm{L}(P<0.01)$.

\section{Discussion}

For the regeneration of injured peripheral nervous system (PNS), SCs play critical roles during this period via the synergetic effects with macrophages and neurons (repairing injured peripheral nerves: bridging the gap). Researches showed that in mammals, after peripheral nerve injury, SCs greatly reduce the expression of myelin [21-24]. At the first day after peripheral nervous damage, SCs digest intracellular myelin debris in the cavity to make the extracellular myelin debris exposure [25-27], which facilitate the macrophage phagocytosis and finally promote the axon regeneration [28]. Therefore, the proliferation of SC is crucial for the repair of peripheral nerve injury in our experiments. When the AE concentration was at $250-2000 \mathrm{mg} / \mathrm{mL}, \mathrm{AE}$ significantly enhanced the proliferation of SCs. However, DP inhibited cell proliferation obviously when the drug concentration exceeded $4000 \mathrm{mg} / \mathrm{L}$. Many researches had demonstrated the extracts of natural plants can accelerate cell proliferation. Normally, they play positive roles when they treat cells within an optimal concentration range. However, negative effects of the same extracts are often observed when the drug-treated concentration is too high $[29,30]$. In order to further test the effects of AE on SCs cycles, SCs were treated with different concentrations of AE in vitro. AE at 500,1000, and $2000 \mathrm{mg} / \mathrm{L}$ promoted the proliferation of SCs significantly, respectively, and elevated the cells counts in S phase and G2/M phase. In SCs, cells in G0/G1 phase were decreased; at the same time, cells in S phase and G2/M phase increased compared with control group. The mechanism of how AE promoted SC proliferation can be inferred. AE shortened the growth retardation, stimulate the cell to enter the active $S$ phase from the stationary G0 phase, and increased the number in G2/M cells, which will lead to the proliferation of cells [31].

Neural factors, such as BDNF, NCAM, and PCNA, play very important roles for the peripheral nerve cell growth, development, and regeneration and maintain the survival of the nerve cells under normal condition. BDNF can promote regeneration of peripheral nerve, protect the damaged neurons and nerve cells, and maintain sensitivity to neurons [32]. $\mathrm{BDNF}$ also regulate and promote synthesis of adhesion in SCs $[33,34]$ and together BDNF and neurotrophic tyrosine receptor kinase type $2(\mathrm{Ntrk} 2)$ are capable of activating the adhesion, angiogenesis, apoptosis, and proliferation pathways [35]. BDNF and NGF play essential roles in central nervous system [36]. NCAM is a kind of immunoglobulin secreted by SCs, and it also has a close relation to the axon regeneration, for example, combining L1 to form L1-NCAM complexes, which enhanced biological functions such as identification and adhesion [37, 38]. NCAM is a signal of glial cell-derived neurotrophic factor (GDNF) family receptors. GDNF activate NCAM and intracellular Fyn and FAK and promote the growth of nerve cells [28]. PCNA protein is essential for cell DNA synthesis, which is closely related to cell proliferation and can effectively reflect the activity of cell proliferation [39]. PCNA is a unique intranuclear protein, 


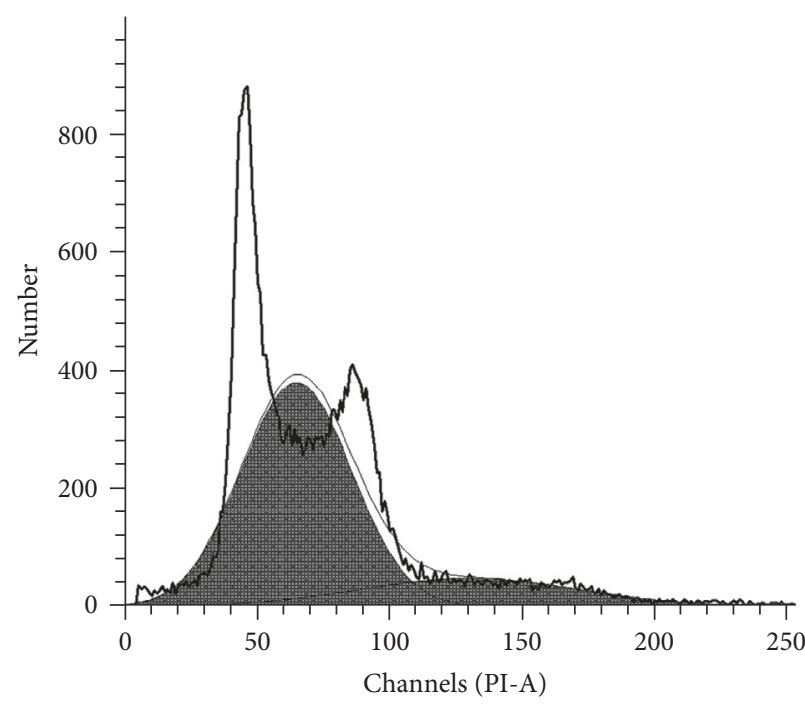

Dip G0-G1

Dip G2-M $\triangle$ Dip S

(a) Control

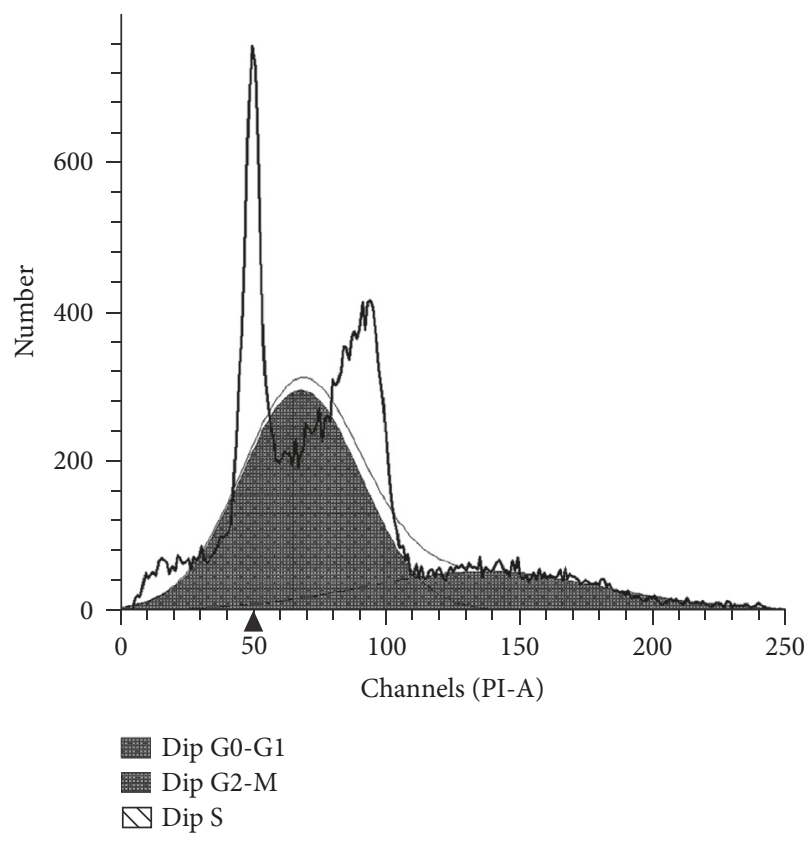

(c) $1000 \mathrm{mg} / \mathrm{L}$

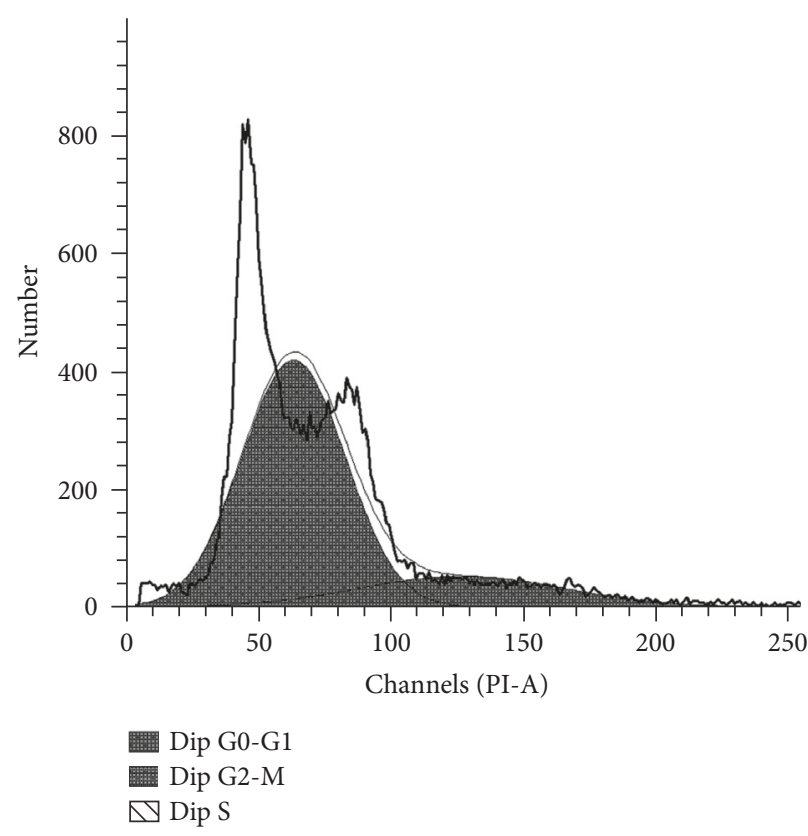

(b) $500 \mathrm{mg} / \mathrm{L}$

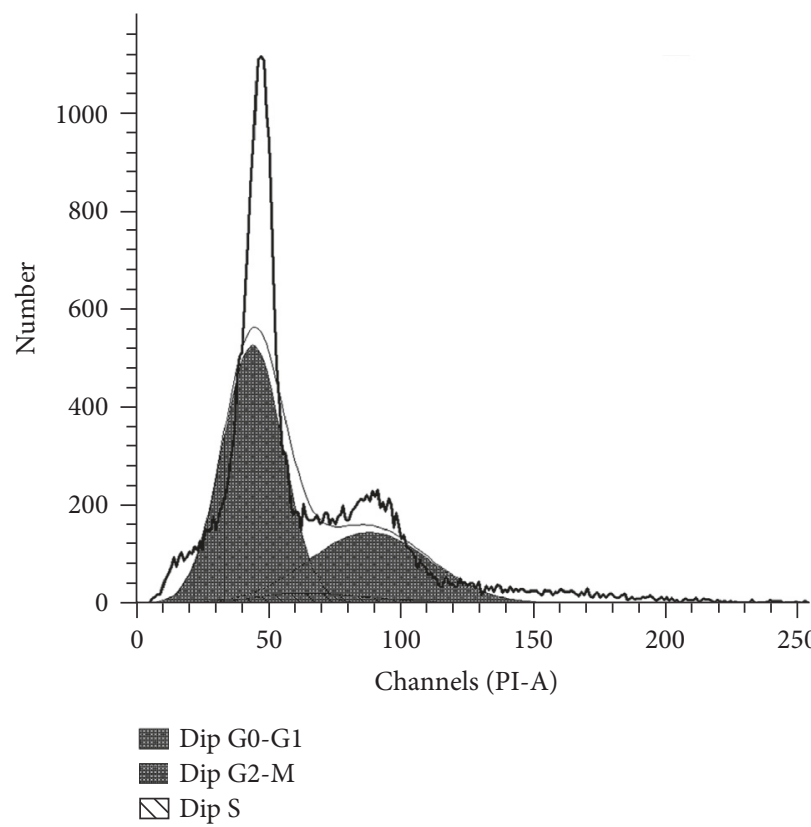

(d) $2000 \mathrm{mg} / \mathrm{L}$

Figure 3: Different concentrations of AE exerted an influence on the SCs cycles ( $24 \mathrm{~h}$ ). SCs were gathered at $24 \mathrm{~h}$ after being treated with 0 , 500,1000 , and $2000 \mathrm{mg} / \mathrm{mL} \mathrm{AE}$, and then SCs cycles were detected using flow cytometry in sequence. The results were shown, respectively, in (a), (b), (c), and (d).

which plays a key role in DNA synthesis, damage healing, and regulation of cell cycle and usually is regarded as cell proliferation index [40]. Expressions of BDNF, NCAM, and PCNA in SCs treated by AE significantly increased compared to control group, and increased mRNA expressions of those were detected by RT-PCR. BDNF plays an essential role in promoting axonal regeneration and remyelination when SCs were transplanted into nerve injury lesions [41]. The overexpression of NCAM promotes neurite outgrowth and is implicated in myelination [42]. The results of PCNA protein upregulation were consistent with SC proliferation assay. These results showed that $\mathrm{AE}$ played an underlying role in peripheral nerve repair through promoting SC proliferation and stimulating SC to secrete neurotrophic factors. However, the active ingredients of Angelica such as polysaccharides, sodium ferulate, and volatile oil need to be further studied. 


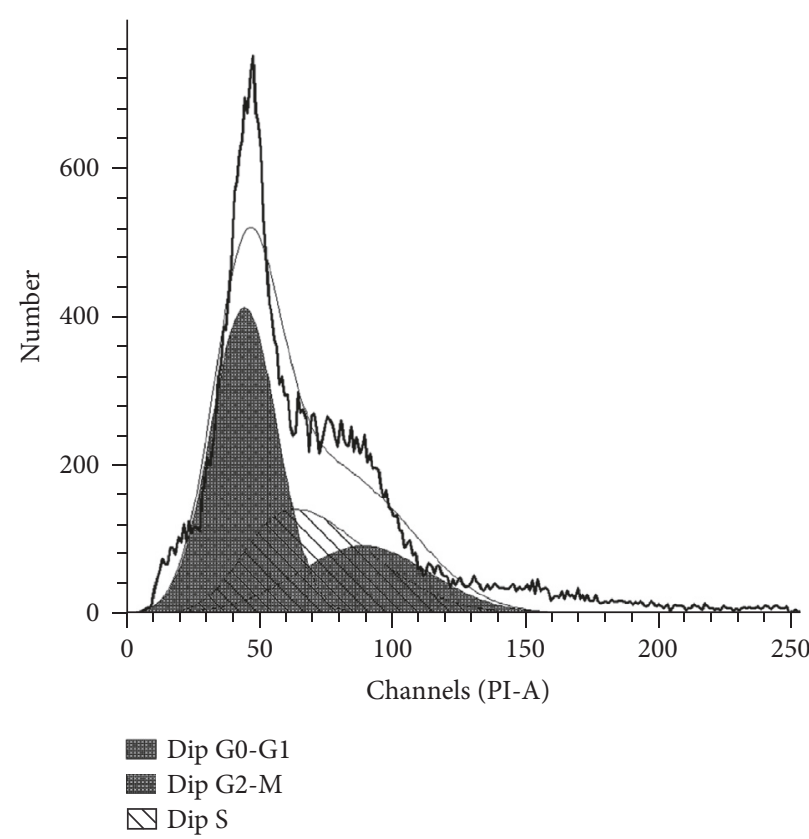

(a) Control

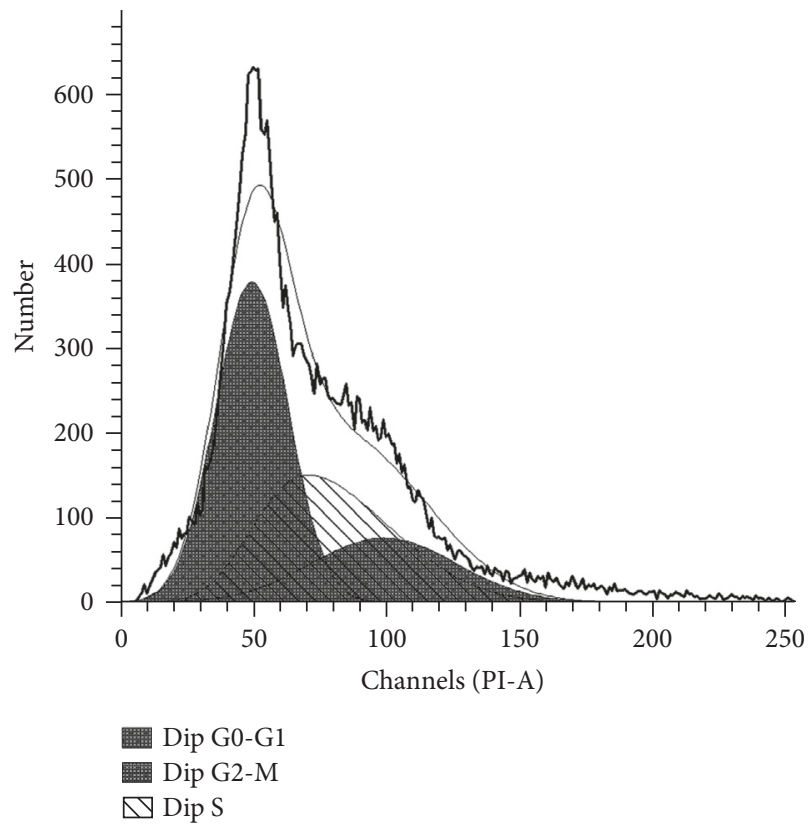

(c) $1000 \mathrm{mg} / \mathrm{L}$

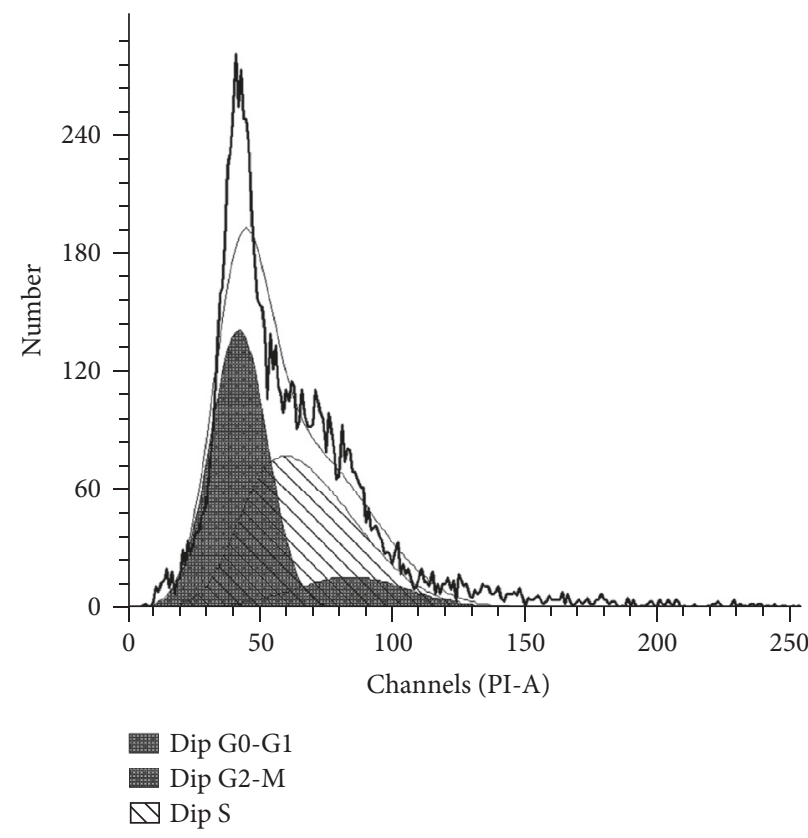

(b) $500 \mathrm{mg} / \mathrm{L}$

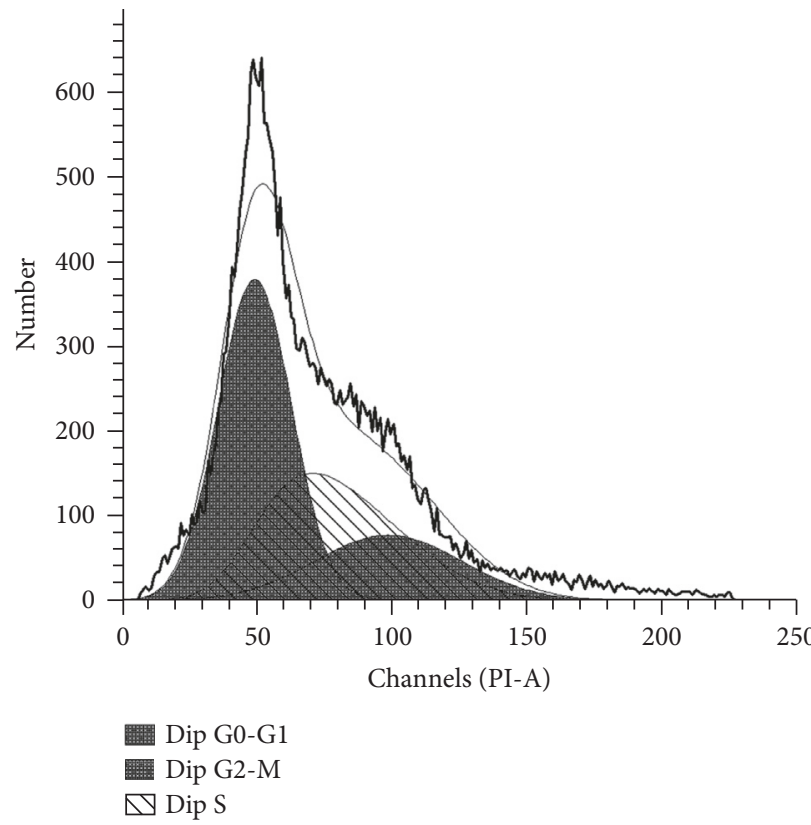

(d) $2000 \mathrm{mg} / \mathrm{L}$

FIGURE 4: Different concentrations of AE exerted an influence on the SCs cycles ( $48 \mathrm{~h}$ )/SCs were gathered at $48 \mathrm{~h}$ after being treated with 0 , 500,1000 , and $2000 \mathrm{mg} / \mathrm{mL} \mathrm{AE}$, and then SCs cycles were detected using flow cytometry in sequence. The results were shown, respectively, in (a), (b), (c), and (d).

\section{Conclusion}

In this work, we demonstrated that AE promoted SC proliferation; furthermore, the results of cell cycle detection showed AE increased significantly DNA percentage in $(\mathrm{G} 2+\mathrm{S})$ phase. Simultaneously BDNF, NCAM, and PCNA protein expressions in SC significantly enhanced with the treatment of $\mathrm{AE}$ for $24 \mathrm{~h}$ or $48 \mathrm{~h}$. Gene expressions of BDNF, NCAM, and
PCNA also were upregulated markedly after drug treatment. Although the effects of AE on nerve repair have been already reported in many researches, we first studied the effects of $\mathrm{AE}$ on SC proliferation and cycle; moreover, many neurological factors which are related to nerve regeneration increased with AE treatment. Taken together, all of these results suggested potential application of $\mathrm{AE}$ in the clinical therapy of nerve injury. 


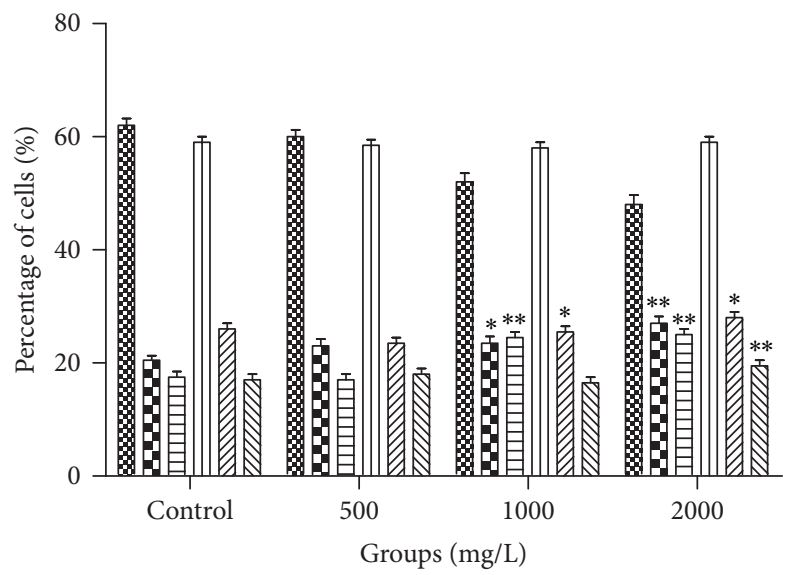

\begin{tabular}{|c|c|}
\hline 24 h G0/G1 phase & एس $48 \mathrm{~h} \mathrm{G0/G1}$ phase \\
\hline 24h S phase & $48 \mathrm{~h} \mathrm{~S}$ phase \\
\hline $24 \mathrm{~h} \mathrm{G} / \mathrm{M}$ phase & $48 \mathrm{~h} \mathrm{G} 2 / \mathrm{M}$ phas \\
\hline
\end{tabular}

FIGURE 5: Effects of different concentrations of AE on SCs cycles $(n=$ $5, \pm \mathrm{s}, \%)$. Modfit LT software was used for analyzing cell cycle of each group after 24 or $48 \mathrm{~h}$ treatment with 500,1000 , and $2000 \mathrm{mg} / \mathrm{mL}$ of AE. Notes: ${ }^{*} P<0.05$ and ${ }^{* *} P<0.01$, as compared with the control group (Student's $t$-test).

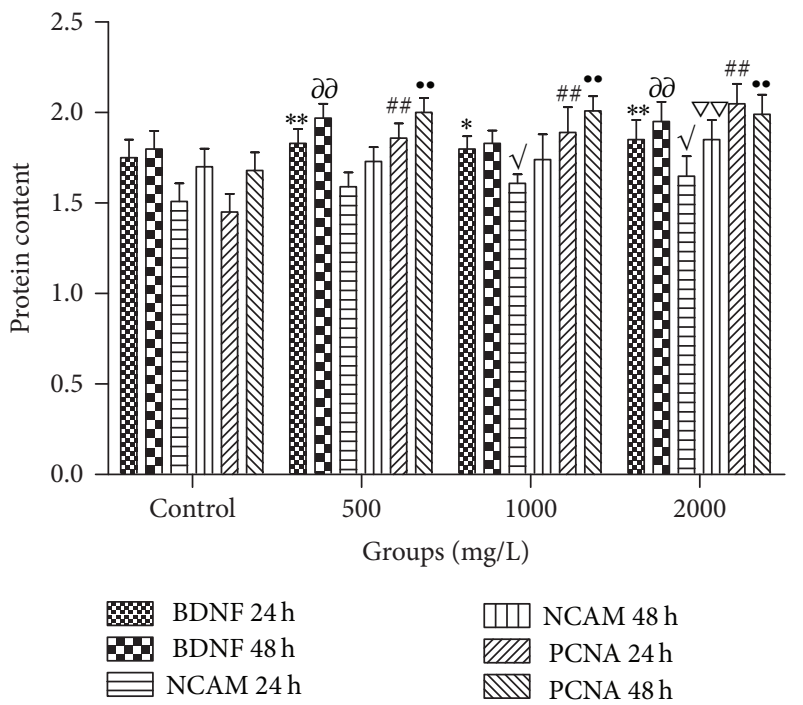

FIGURE 6: Effects of different concentrations of AE on expressions of the relative secretion cytokine of SCs $(n=5, \pm s)$. BDNF, NCAM, and PCNA expressions were detected by ELISA kits at 24 and $48 \mathrm{~h}$ after stimulation without or with indicated concentrations of AE. Notes: single symbol such as "*" means $P<0.05$ compared with control; double symbols such as “**” mean $P<0.01$ compared with control.

\section{Conflicts of Interest}

The authors declare that they have no financial and personal relationships with other people or organizations that can inappropriately influence their work and there is no professional or other personal interest of any nature or kind in any product, service, or company.
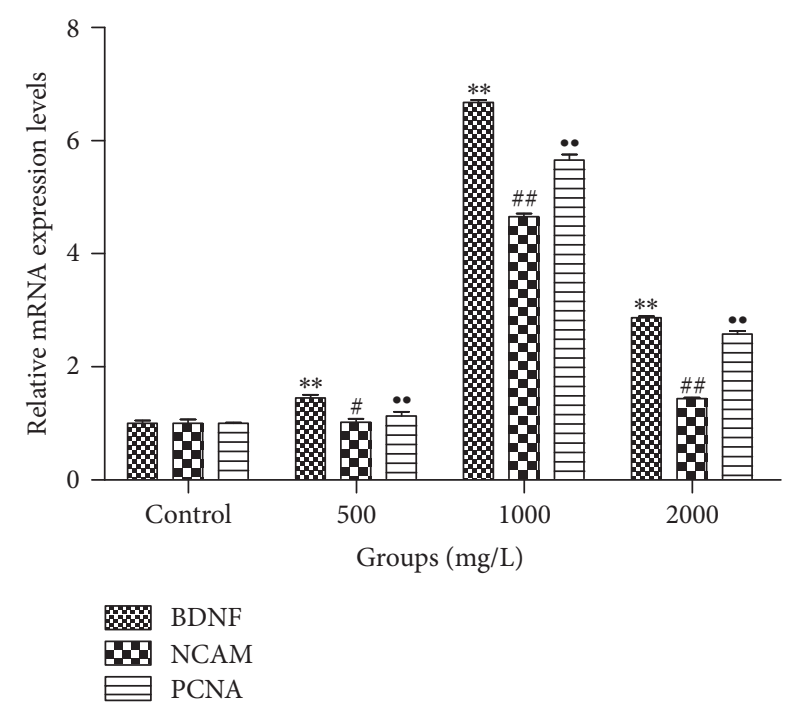

FIGURE 7: Effects of different concentrations of AE on mRNA expressions of BDNF, NCAM, and PCNA in SCs $(n=4, \pm s)$. AE interfered with SCs growths for $48 \mathrm{~h}$ at concentrations of 500, 1000, and $2000 \mathrm{mg} / \mathrm{L}$, respectively; gene expressions of BDNF, NCAM, and PCNA were checked by RT-PCR. Results were presented as the folds change compared with untreated cells. Notes: ${ }^{*, \# \bullet} P<0.05$ compared with control group; ${ }^{* *, \#, * \bullet} P<0.01$ compared with control group (Student's $t$-test). “*” and “•” refer to differences in each gene expression between control group and drug-treated groups.

\section{Authors' Contributions}

Xiaowen Jiang and Lin Liu contributed equally to this work. Wenhui Yu and Xiaowen Jiang designed experiments; Lin Liu and Xiaowen Jiang carried out experiments mainly; Binqing Zhang and Lu Qiao analyzed experimental results. Ziyin Lu, Lin Liu, and Xinxin Feng wrote the manuscript together.

\section{Acknowledgments}

The authors thank Professor Li for her equipment and instrument support. They also express heartfelt thanks to Dr. Shi for assistance with the experiments and valuable discussion.

\section{References}

[1] U. Namgung, "The role of schwann cell-axon interaction in peripheral nerve regeneration," Cells Tissues Organs, vol. 200, no. 1, pp. 6-12, 2014.

[2] A. Cattin, "Macrophage-induced blood vessels guide schwann cell-mediated regeneration of peripheral nerves," Cell, vol. 162, no. 5, pp. 1127-1139, 2015.

[3] F. Liu, H. W. Zhang, K. M. Zhang, X. Y. Wang, S. P. Li, and Y. X. Yin, "Rapamycin promotes Schwann cell migration and nerve growth factor secretion," Neural Regeneration Research, vol. 9, no. 6, pp. 602-609, 2014.

[4] A. M. Avellino, D. Hart, A. T. Dailey, M. Mackinnon, D. Ellegala, and M. Kliot, "Differential macrophage responses in the peripheral and central nervous system during wallerian 
degeneration of axons," Experimental Neurology, vol. 136, no. 2, pp. 183-198, 1995.

[5] D. J. Carey and R. P. Bunge, "Factors influencing the release of proteins by cultured Schwann cells," Journal of Cell Biology, vol. 91, no. 3, part 1, pp. 666-672, 1981.

[6] H. Fansa, T. Dodic, G. Wolf, W. Schneider, and G. Keilhoff, "Tissue engineering of peripheral nerves: epineurial grafts with application of cultured Schwann cells," Microsurgery, vol. 23, no. 1, pp. 72-77, 2003.

[7] Y. Y. Choi, M. H. Kim, J. Hong, K. Kim, and W. M. Yang, "Effect ofDangguibohyul-Tang, a Mixed Extract ofAstragalus membranaceusandAngelica sinensis, on allergic and inflammatory skin reaction compared with single extracts of astragalus membranaceusor angelica sinensis," Evidence-Based Complementary and Alternative Medicine, vol. 2016, pp. 1-9, 2016.

[8] J. Xu, E. Xiao-Qiang, H.-Y. Liu, J. Tian, and J.-L. Yan, “Angelica sinensis attenuates inflammatory reaction in experimental rat models having spinal cord injury," International Journal of Clinical and Experimental Pathology, vol. 8, no. 6, pp. 67796785, 2015.

[9] S. Zheng, W. Ren, and L. Huang, "Geoherbalism evaluation of Radix Angelica sinensis based on electronic nose," Journal of Pharmaceutical and Biomedical Analysis, vol. 105, pp. 101-106, 2015.

[10] C.-Y. Hsiao, C.-Y. Hung, T.-H. Tsai, and K.-F. Chak, "A study of the wound healing mechanism of a traditional chinese medicine, Angelica sinensis, using a proteomic approach," Evidence-Based Complementary and Alternative Medicine, vol. 2012, Article ID 467531, 14 pages, 2012.

[11] R. Li, J. Zhang, L. Zhang, Q. Cui, and H. Liu, "Angelica injection promotes peripheral nerve structure and function recovery with increased expressions of nerve growth factor and brain derived neurotrophic factor in diabetic rats," Current Neurovascular Research, vol. 7, no. 3, pp. 213-222, 2010.

[12] J. Wang, X.-Y. Qiao, and F. Lin, "Present situation and development strategies of Chinese medicine preparation in medical institutions," China Journal of Chinese Materia Medica, vol. 40, no. 21, pp. 4117-4121, 2015.

[13] R. Li, C. Zhao, M. Yao, Y. Song, Y. Wu, and A. Wen, "Analgesic effect of coumarins from Radix angelicae pubescentis is mediated by inflammatory factors and TRPV1 in a spared nerve injury model of neuropathic pain," Journal of Ethnopharmacology, vol. 195, pp. 81-88, 2017.

[14] Q. Cui, J. Zhang, L. Zhang, R. Li, and H. Liu, "Angelica injection improves functional recovery and motoneuron maintenance with increased expression of brain derived neurotrophic factor and nerve growth factor," Current Neurovascular Research, vol. 6, no. 2, pp. 117-123, 2009.

[15] Y. J. Moon, J. Y. Lee, M. S. Oh et al., "Inhibition of inflammation and oxidative stress by Angelica dahuricae radix extract decreases apoptotic cell death and improves functional recovery after spinal cord injury," Journal of Neuroscience Research, vol. 90, no. 1, pp. 243-256, 2012.

[16] M. H. Jeong, J. S. Kim, Y. Zou et al., "Enhancement of pheochromocytoma nerve cell growth by consecutive fractionization of Angelica gigas Nakai extracts," Cytotechnology, vol. 62, no. 5, pp. 461-472, 2010.

[17] S. Gnavi, B. Elena Fornasari, C. Tonda-Turo et al., "The effect of electrospun gelatin fibers alignment on schwann cell and axon behavior and organization in the perspective of artificial nerve design," International Journal of Molecular Sciences, vol. 16, no. 6, pp. 12925-12942, 2015.
[18] S. Geuna, S. Raimondo, S. Nicolino et al., "Schwann-cell proliferatin in muscle-vein combined conduits for bridging rat sciatic nerve defects," Journal of Reconstructive Microsurgery, vol. 19, no. 2, pp. 119-123, 2003.

[19] S. Han, B. Wang, W. Jin et al., "The collagen scaffold with collagen binding BDNF enhances functional recovery by facilitating peripheral nerve infiltrating and ingrowth in canine complete spinal cord transection," Spinal Cord, vol. 52, no. 12, pp. 867873, 2014.

[20] F. Klaiber, B. Schönfeld, and G. Kostorz, "Brief transvertebral electrical stimulation of the spinal cord improves the specificity of femoral nerve reinnervation," Neurorehabilitation and Neural Repair, vol. 27, no. 3, pp. 260-268, 2013.

[21] C. De Felipe and S. P. Hunt, "The differential control of c-jun expression in regenerating sensory neurons and their associated glial cells," Journal of Neuroscience, vol. 14, no. 5, part 1, pp. 29112923, 1994.

[22] B. D. Trapp, P. Hauer, and G. Lemke, "Axonal regulation of myelin protein mRNA levels in actively myelinating Schwann cells," Journal of Neuroscience, vol. 8, no. 9, pp. 3515-3521, 1988.

[23] P. J. Arthur-Farraj, M. Latouche, D. K. Wilton et al., "c-Jun reprograms Schwann cells of injured nerves to generate a repair cell essential for regeneration," Neuron, vol. 75, no. 4, pp. 633647, 2012.

[24] K. R. Jessen and R. Mirsky, "Negative regulation of myelination: relevance for development, injury, and demyelinating disease," Glia, vol. 56, no. 14, pp. 1552-1565, 2008.

[25] M. H. Han, Y. J. Piao, D. W. Guo, and K. Ogawa, "The role of Schwann cells and macrophages in the removal of myelin during Wallerian degeneration," Acta Histochemica Et Cytochemica Official Journal of the Japan Society of Histochemistry \&amp; Cytochemistry, vol. 22, no. 2, pp. 161-172, 1989.

[26] K. Hirata and M. Kawabuchi, "Myelin phagocytosis by macrophages and nonmacrophages during Wallerian degeneration," Microscopy Research and Technique, vol. 57, no. 6, pp. 541547, 2002.

[27] H. Mei Liu, L. H. Yang, and Y. J. Yang, "Schwann cell properties: 3. U-fos expression, bFGF production, phagocytosis and proliferation during wallerian degeneration," Journal of Neuropathology and Experimental Neurology, vol. 54, no. 4, pp. 487-496, 1995.

[28] G. Paratcha, F. Ledda, and C. F. Ibáñez, "The neural cell adhesion molecule NCAM is an alternative signaling receptor for GDNF family ligands," Cell, vol. 113, no. 7, pp. 867-879, 2003.

[29] J. W. Ren, K. M. Chan, P. K. K. Lai et al., "Extracts from Radix Astragali and Radix Rehmanniae promote keratinocyte proliferation by regulating expression of growth factor receptors," Phytotherapy Research, vol. 26, no. 10, pp. 1547-1554, 2012.

[30] B. H. I. Ruszymah, S. R. Chowdhury, N. A. B. A. Manan, O. S. Fong, M. I. Adenan, and A. B. Saim, "Aqueous extract of Centella asiatica promotes corneal epithelium wound healing in vitro," Journal of Ethnopharmacology, vol. 140, no. 2, pp. 333338, 2012.

[31] C. Webber and D. Zochodne, “The nerve regenerative microenvironment: early behavior and partnership of axons and Schwann cells," Experimental Neurology, vol. 223, no. 1, pp. 5159, 2010.

[32] Y. Takemura, S. Imai, H. Kojima et al., "Brain-derived neurotrophic factor from bone marrow-derived cells promotes post-injury repair of peripheral nerve," PLoS ONE, vol. 7, no. 9, Article ID e44592, 2012. 
[33] M. Meyer, I. Matsuoka, C. Wetmore, L. Olson, and H. Thoenen, "Enhanced synthesis of brain-derived neurotrophic factor in the lesioned peripheral nerve: different mechanisms are responsible for the regulation of BDNF and NGF mRNA," The Journal of Cell Biology, vol. 119, no. 1, pp. 45-54, 1992.

[34] C. Géral, A. Angelova, and S. Lesieur, "From molecular to nanotechnology strategies for delivery of neurotrophins: emphasis on brain-derived neurotrophic factor (BDNF)," Pharmaceutics, vol. 5, no. 1, pp. 127-167, 2013.

[35] J. M. Wessels, L. Wu, N. A. Leyland, H. Wang, and W. G. Foster, "The brain-uterus connection: brain Derived Neurotrophic Factor (BDNF) and its receptor (Ntrk2) are conserved in the mammalian uterus," PLoS ONE, vol. 9, no. 4, Article ID e94036, 2014.

[36] S. Coskun, S. Varol, H. H. Ozdemir, E. Agacayak, B. Aydın, O. Kapan et al., "Association of brain-derived neurotrophic factor and nerve growth factor gene polymorphisms with susceptibility to migraine," Neuropsychiatric Disease and Treatment, vol. 12, no. 1, pp. 1779-1785, 2016.

[37] M. Dezawa, K. Kawana, and E. Adachi-Usami, "The role of Schwann cells during retinal ganglion cell regeneration induced by peripheral nerve transplantation," Investigative Ophthalmology \& Visual Science, vol. 38, no. 7, pp. 1401-1410, 1997.

[38] R. Kleene, C. Cassens, R. Bähring et al., "Functional consequences of the interactions among the neural cell adhesion molecule NCAM, the receptor tyrosine kinase TrkB, and the inwardly rectifying K+ channel KIR3.3," Journal of Biological Chemistry, vol. 285, no. 37, pp. 28968-28979, 2010.

[39] S. Bhattacharya, N. Muhammad, R. Steele, G. Peng, and R. B. Ray, "Immunomodulatory role of bitter melon extract in inhibition of head and neck squamous cell carcinoma growth," Oncotarget, vol. 7, no. 22, pp. 33202-33209, 2016.

[40] X. Xu, C. Yan, B. R. Kossmann, and I. Ivanov, "Secondary interaction interfaces with PCNA control conformational switching of DNA polymerase PolB from polymerization to editing," Journal of Physical Chemistry B, vol. 120, no. 33, pp. 8379-8388, 2016.

[41] C. Tep, M. L. Kim, L. I. Opincariu et al., "Brain-derived neurotrophic factor (BDNF) induces polarized signaling of small GTPase (Racl) protein at the onset of schwann cell myelination through partitioning-defective 3 (Par3) protein," The Journal of Biological Chemistry, vol. 287, no. 2, pp. 1600$1608,2012$.

[42] A. A. Lavdas, J. Chen, F. Papastefanaki et al., "Schwann cells engineered to express the cell adhesion molecule L1 accelerate myelination and motor recovery after spinal cord injury," Experimental Neurology, vol. 221, no. 1, pp. 206-216, 2010. 


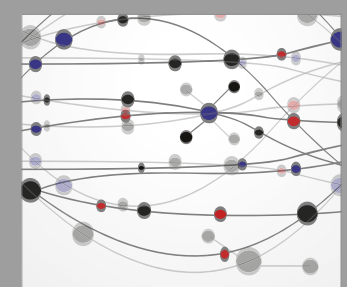

The Scientific World Journal
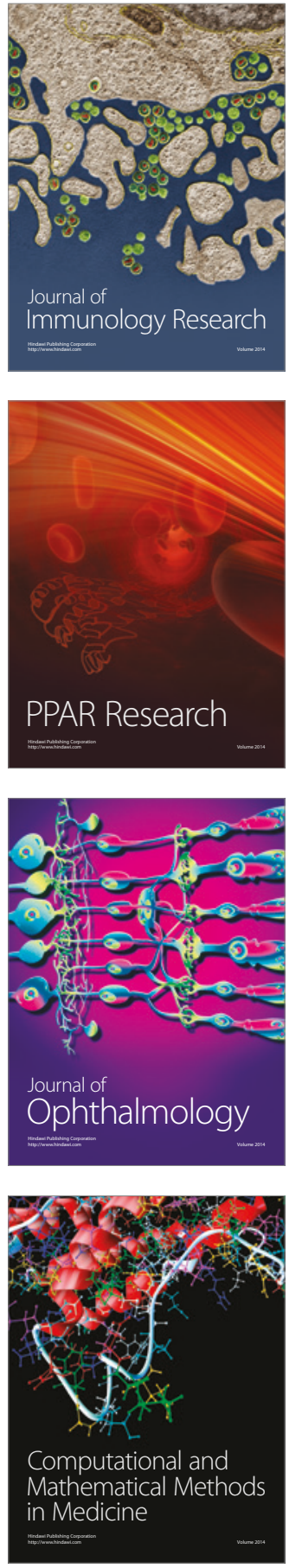

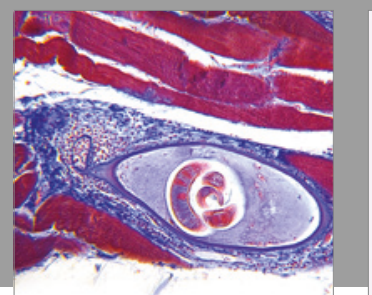

Gastroenterology Research and Practice
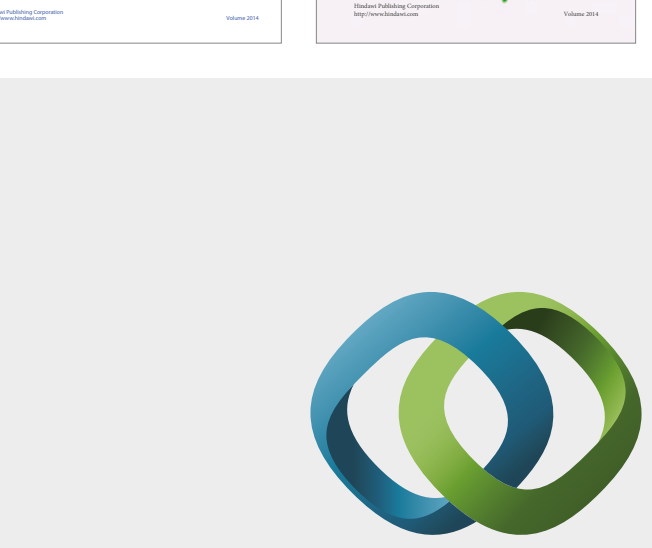

\section{Hindawi}

Submit your manuscripts at

https://www.hindawi.com
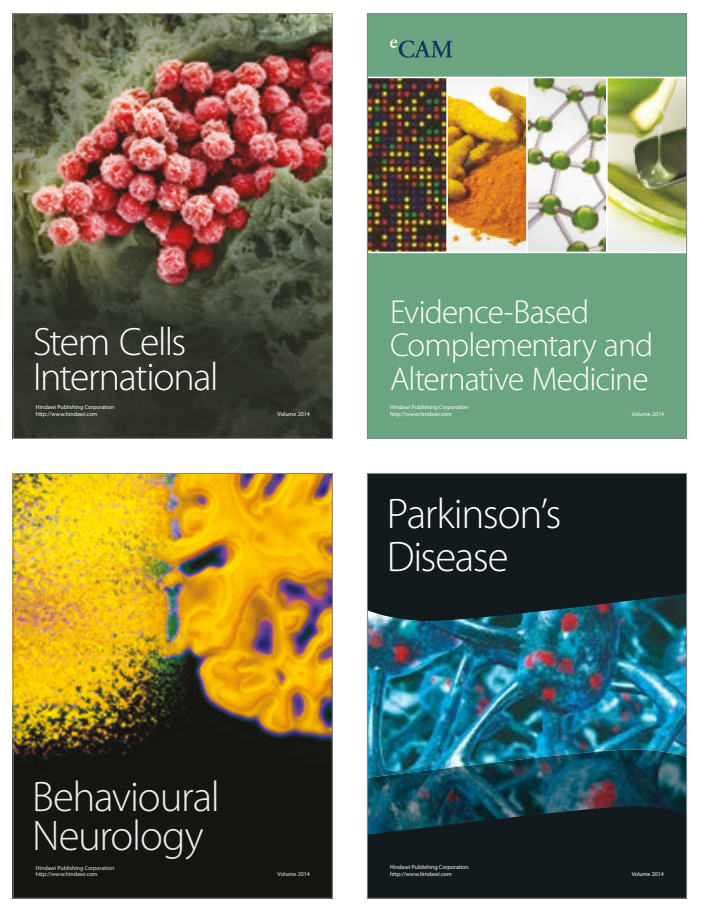
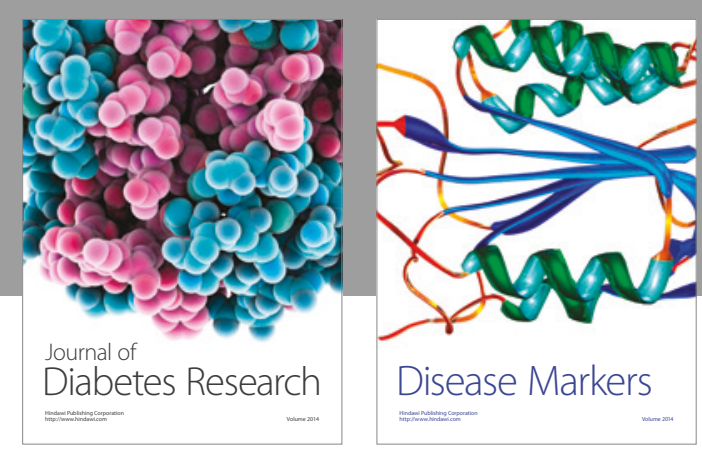

Disease Markers
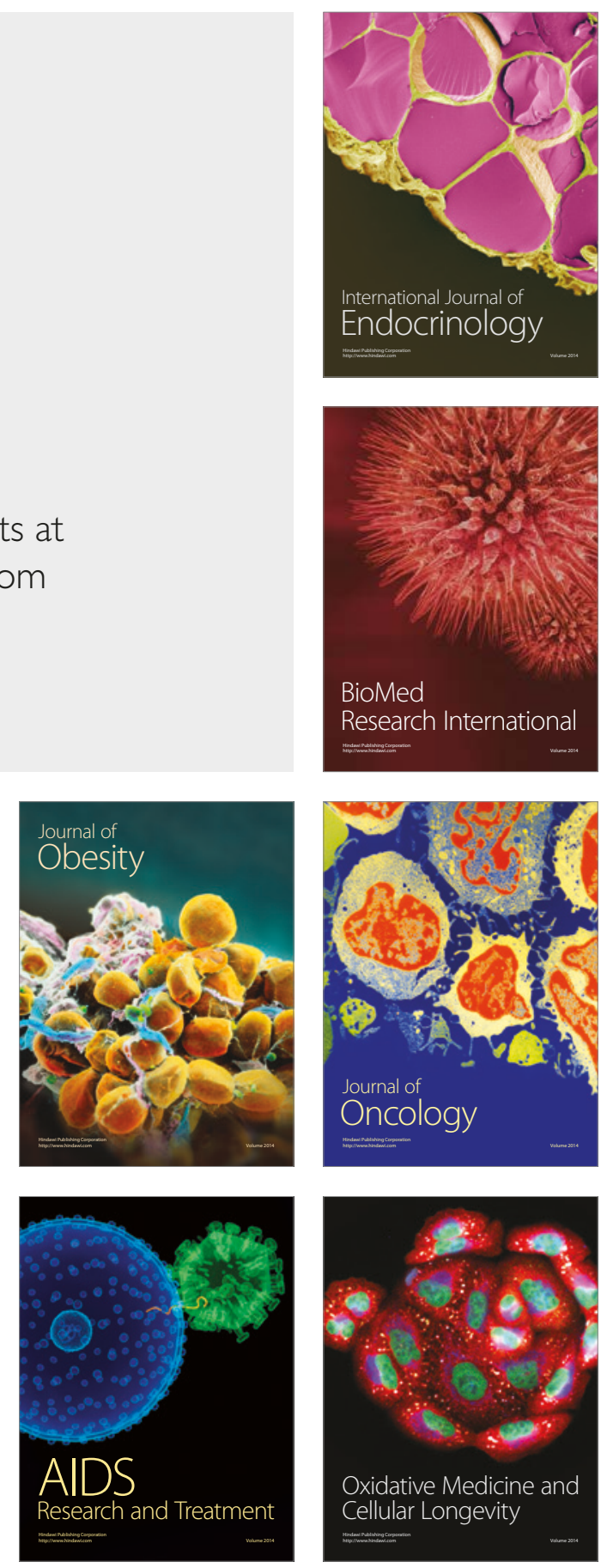